\title{
Association of biomass fuel use with acute respiratory infections among under- five children in a slum urban of Addis Ababa, Ethiopia
}

Habtamu Sanbata ${ }^{1 *}$, Araya Asfaw ${ }^{2}$ and Abera Kumie ${ }^{3}$

\begin{abstract}
Background: Indoor air pollution from biomass fuel is responsible for 50,320 annual deaths of children under-five year, accounting for $4.9 \%$ of the national burden of disease in Ethiopia. Acute respiratory infections are the leading cause of mortality among children in Ethiopia. There is limited research that has examined the association between the use of biomass fuel and acute respiratory infections among children.

Methods: A community based cross-sectional study was conducted during January to February 2012 among 422 households in the slum of Addis Ababa. Data were collected by using structured and pretested questionnaire. Odds ratio was done to determine association between independent variables and acute respiratory infections by using logistic regression analysis. Multivariate logistic regression was used to determine the presence of an association between biomass fuel use and acute respiratory infections after controlling for other confounding variables.

Results: Nearly 253 (60\%) of children live in households that predominately used biomass fuel. The two weeks prevalence of acute respiratory infection was $23.9 \%$. The odds ratios of acute respiratory infection were 2.97 (95\% Cl: 1.38-3.87) and 1.96 (95\% Cl: 0.78-4.89) in households using biomass fuel and kerosene, respectively, relative to cleaner fuels.
\end{abstract}

Conclusion: There is an association between biomass fuel usage and acute respiratory infection in children. The relationship needs investigation which measure indoor air pollution and clinical measures of acute respiratory infection.

Keywords: Biomass fuel, Acute respiratory infection, Children, Slum, Addis Ababa, Ethiopia

\section{Background}

Household energy affects health of the poor through a variety of physical, social and economic aspects. The most important direct health effect results from indoor air pollution (IAP) produced by burning biomass fuels and coal in simple stoves with inadequate ventilation [1]. Worldwide, more than three billion people depend on solid fuels, including biomass (wood, dung, crop residues, coal) for cooking and heating [2]. IAP is responsible for more than 1.6 million deaths annually and $2.7 \%$ of the

\footnotetext{
* Correspondence: habtish217@gmail.com

'Department of Public and Environmental Health, College of Medicine and Health Science, Hawassa University, Hawassa, Ethiopia

Full list of author information is available at the end of the article
}

global burden of disease. Acute respiratory infections (ARI) are the biggest killer of young children [1].

Biomass fuels are at the low end of the energy ladder in terms of combustion efficiency and cleanliness. Biomass combustion produces a large number of health-damaging air pollutants including respirable particulate matter, carbon monoxide (CO), nitrogen oxides, formaldehyde, benzene, 1,3 butadiene, polycyclic aromatic hydrocarbons (PAHs)and many other toxic organic compounds [3].

Over 70 percent of energy needs in most of the subSaharan African countries are met by biomass fuels, mainly for the household. The efficiency of fuel wood used for cooking in developing countries is quite low, leading to energy requirements that are several times 
higher than in developed countries [4]. Developing countries are significantly affected by the problem due to their increased use of polluting energy sources for their energy demands. World Health Organization (WHO) estimates on burden of diseases for the year 2002, IAP from biomass use accounted for $3.7 \%$ of the burden of disease in developing countries [1].

In Ethiopia, about $95 \%$ of the country's energy supply comes from biomass sources [5]. IAP from biomass fuel is responsible for 50,320 annual ARI deaths of children under-five year, accounting $4.9 \%$ of national burden of disease in Ethiopia [1]. The estimated energy consumption per household in Addis Ababa is approximately 7 GJ, slightly less than half the per capita consumption. Traditional fuels (fuel wood, charcoal and dung) meet about $75 \%$ of household energy needs. Kerosene, Liquefied Petroleum Gas (LPG) and electricity provide the remaining 25\%. In the last decade, kerosene use in Addis Ababa has declined considerably as a result of a doubling in the cost of kerosene, largely because of the removal of subsidies. At the same time, the price of electricity has declined by more than $50 \%$ and it is currently sold at approximately $75 \%$ less than the price of kerosene [6]. A large proportion of kerosene users have shifted to fuel wood [7].

Recent study conducted in Addis Ababa indicated the average fine particulate matter $\left(\mathrm{PM}_{2.5}\right)$ concentration measured in homes using biomass fuel far exceeded WHO guidelines [7]. The city highest 24-hour geometric mean of $\mathrm{PM}_{2.5}$ concentrations observed in households using predominantly biomass fuel, kerosene, and clean fuel are $1,134 \mu \mathrm{g} / \mathrm{m}^{3}$ (SD = 3.36), $637 \mu \mathrm{g} / \mathrm{m}^{3}$ ( $\left.\mathrm{SD}=4.44\right)$, and $335 \mu \mathrm{g} / \mathrm{m}^{3}(\mathrm{SD}=2.51)$ respectively [7]. Thus, the IAP in the city is high. Biomass fuel will continue to be used by a large number of households for the foreseeable future. The burden of disease due to IAP is exceedingly affecting children in poor slum urban households in Addis Ababa. There is limited evidence that link biomass fuel use with ARI among under-five children in Ethiopia. The aim of this study was to assess the association of biomass fuel and ARI among children under-five in the urban slum of Addis Ababa.

\section{Methods}

\section{Study design and setting}

A community based quantitative cross- sectional study was conducted to answer the research objectives. Data were collected using structured questionnaire by administering face to face interviewing of mothers. The study was conducted in Addis Ababa, the capital city of Ethiopia. The city is situated at the center of the country at an altitude varying between 2,200 and 2,800 meters above sea level (masl), between latitude $9.0300^{\circ} \mathrm{N}$ and longitude $38.7400^{\circ}$ E. Average annual temperatures range from $8.2^{\circ} \mathrm{C}$ to $25.1^{\circ} \mathrm{C}$. The administrative structure of the city Addis Ababa has 10 sub-cities and 116 districts (woredas). The city has a projected population of approximately 3.4 million people and over 500,000 households with an average family size of six. With an estimated area of 530.14 square kilometers, this chartered city has an estimated density of 5,165.1 inhabitants per square kilometer [8]. An estimated $80 \%$ of the population in Addis Ababa lives in poor and overcrowded districts [9]. The study unit embraced all households with underfive children. Sampling units were households with children under five years in Addis Ababa.

\section{Sample size and sampling procedure}

The sample size was calculated using a single population proportion formula using the following parameters: $95 \%$ confidence level (1.96), margin of error (0.05), expected prevalence of children with acute respiratory infection $50 \%$. With this assumption a total of 422 household with children under- five were included in this study. The sampling procedure involved a three-staged sampling scheme aimed at obtaining 106 households in each selected sub-city using a probability to population size. A sub-city is the largest administrative structure in the city. In the first stage, total ten sub-cities were stratified into four based on similarity of crowdedness, housing situation and sanitation coverage of the city. From each strata one sub-city was selected by lottery method and thus four total sub-cities were selected from ten of the city. In the second stage, each Districts (Woredas) was clustered and three districts (woredas) from each of the four cities (total 12 districts) were selected targeting 34 to 37 households per district (woreda). In the third stage selection of houses having under-five children was conducted by using systematic random sampling method. This process have been then followed by a complete household listing operation, which was carried out in all the selected district (woreda) to provide a sampling frame for the third -stage selection of households with children under- five years.

\section{Data collection method}

Data were collected during January to February 2012 through structured questionnaire through interviewing mothers of under- five children. The questionnaire was developed after critical discussions with public health experts. The questionnaire was adapted from WHO guidelines for survey of household fuel use [10] and for ARI module [11].

Data collectors were community health extension workers with similar professional experience. The data collectors were extensively trained by the principal investigator and a pediatrician for two days on interviewing techniques, observational, data recording, approaches to promote health education, and advocacy of child health 
screening. One professional expert was assigned in each sub-city for monitoring and supervision of data collection.

\section{Predictor variables}

Information on types of fuel used for cooking was gathered. To elicit this information the question "What type of fuel does your household mainly use for cooking?" was asked. The question was then followed by a list of different fuel names to choose from. The choice include fuel wood, crop residues, dung cakes, charcoal, kerosene, Liquefied Petroleum Gas (LPG) and electricity. Exposure assessment questions also collected on socio demographic like sex of household head, family size, education level, cigarettes smoking habit, housing characteristics, type of stove used and ventilation efficiency, behavioral measures, most commonly whether child is carried by the mother while she is cooking also time spent near fire, and child stays in smoke, questions on location of the child relative to cooking place, cooking done in same room as where children sleeping were included. Use of biomass fuels kerosene, LPG and electricity is the main independent variable of the study.

\section{Child health screening}

Questionnaire respondents were residents who voluntarily agreed to participate upon having the purpose of the research explained. Mothers were asked to describe the health status of children under five year within the household with respect to ARI. First, mothers were asked whether there were any children who were coughing. If the answer was yes, mothers were asked to describe the breathing (i.e.: short and/or rapid breathing). Children who suffered from coughs, accompanied by chest in drawing, shortness of breath, and rapid breathing were diagnosed with an acute respiratory infection, according to the WHO clinical case definition [11]. Suffering from ARI was the dependent variable used in this study.

\section{Operational definition}

\section{Acute respiratory infection (ARI)}

This study uses the WHO definition, which defines ARI to include any combination of the following symptoms: cough with or without fever, blocked or runny nose, sore throat, and/or ear discharge with infection of the lungs. Serious forms of ARI result in pneumonia or bronchopneumonia [11]. Therefore, acute respiratory infections refer to upper respiratory and lower respiratory infections.

\section{Acute lower respiratory infection}

Serious form of ARI, resulting in pneumonia or bronchopneumonia.

\section{Acute upper respiratory infection}

Infection of the upper respiratory tract involving larynx, pharynx, tonsillar glands, Eustachian tube, nasal cavities and sinuses.

\section{Fuel type}

Fuel type refers to the source of energy used for cooking and was classified into three categories: biomass fuels (wood, dung cakes, charcoal, urban residues), kerosene, and clean fuel (LPG and electricity).

\section{Improved cook stove}

There is no international definition for the exact fuel savings that are necessary for a stove to be considered as an improved stove. However, an improved cook stove is a device that is designed to consume less fuel, save time, reduce the volume of smoke produced compared to the traditional stove.

\section{Traditional cook stove}

There is no universally accepted definition for traditional cook stoves that is linked to performance or technical standards. Thus, throughout this paper, the term refers to cook stoves constructed by household members that are not energy efficient and have poor combustion features using for cooking purpose.

\section{Clean stove}

Refers to efficient, safe, durable, and affordable stoves that use clean fuels. It includes both electric and LPG stoves.

\section{Indoor air pollution}

Indoor air pollution refers to the toxic emissions from cooking, especially from the use of wood, dung, charcoal, kerosene and other cooking fuels.

\section{Cigarette smoking}

Refers to any member of the household that smokes more than one cigarette a day at home.

\section{Ventilation}

Refers to the process of supplying or removing air from any enclosed space by natural or mechanical means. In this study, ventilation is measured by households that have properly built doors, windows (fanlight, hopper, or sliding sash windows), or mechanical apparatuses (fans and air conditioner).

\section{Data quality assurance}

The questionnaire was written in English and administered in Amharic, the local language, by linguistic professionals. It was validated by independent repeat administration on consecutive days in approximately $10 \%$ of the households. 
The pre-test was conducted among 5\% of the respondents to test the efficacy of the research instruments and to discover possible weaknesses, inadequacies, and ambiguities so that they was able to corrected before actual data collection started. Data collection was overseen by a field supervisor who cross-check all field forms after each day of data collection to ensure that the forms were completely filled and data were consistent. Any mistake or omission was corrected as on the same day of data collection. Double data entry was used to check any inconsistency in responses from respondents.

\section{Data management and analysis}

Coded data entry was done in EPI INFO version 6.04 for data clearance and skip pattern prior to analysis using the SPSS (Statistical Package of Social Science) Version 20.0 package. Cleaning was made to avoid missing values, outliers and other inconsistencies. Consistency and completeness of data were checked using frequency and a 2 by 2 tables. Descriptive statistics such as frequency distributions and measure of central tendencies were calculated for dependent and independent variables. Bivariate and multivariate analysis using binary logistic regressions were done to determine the presence of a statistically significant association between explanatory variables and the outcome variables. Crude Odds Ratio (OR) with 95\% Confidence Intervals (CI) was done to determined association between independent variables and ARI. The multivariate logistic regression analysis was done using enter method hierarchically to assess the relative effect of the explanatory factors on acute respiratory infection. Multivariate logistic regressions analyses were used to determine the presence of an association between explanatory variables and acute respiratory infections by controlling the effect of other variables. To limit many variables and unstable estimates in the subsequent models, only variables that reached a p-value less than 0.30 at the bivariate analysis level were kept in the model. Data were presented using figures and tables.

\section{Ethical consideration}

The study had ethical approval from Addis Ababa University and Health office of Addis Ababa. The study was in words communicated to each respondent and verbal consent was secured once agreement on the interview was obtained. Inconveniences for refusals were respected. Children whom found in their households with severe pneumonia were referred for treatment to near health institution. Results of the study will be planned to be communicated to the local authorities and community.

\section{Results}

Socio-demographic characteristics

A total of 422 samples in Addis Ababa households were involved in this study. The overall average family size was 5 persons per household. There were 285 (67.5\%) male head of households and 137 (32.5\%) were femaleheaded. The marital status distribution of house hold head were344 (81.5\%) married, 31 (7.3\%) single, 26 (6.2\%) divorced, and $21(5.0 \%)$ were widowed. The religion of the households head were predominantly Orthodox Christian and Muslim, 264 (62.6\%) and 106 (25.1\%) respectively, the remaining 52 (12.3\%) were Protestant.

In terms of smoking habit, $62(14.7 \%)$ had at least one member within the household who smokes more than one cigarette a day at home compared with 360 (85.3\%) non-smokers (see Table 1).

Regarding the housing units, 224 (53.0\%) of the kitchens were attached to the house and 198 (47.0\%) were detached from the house. About 203 (48.0\%) households cook in a

Table 1 Socio-demographic characteristic of sampled households in Addis Ababa, February 2012

\begin{tabular}{|c|c|c|c|}
\hline Socio demographics & & Frequency & Percent \\
\hline Response rate & & 422 & 100 \\
\hline Sex of the household & Male & 285 & 67.5 \\
\hline & Female & 137 & 32.5 \\
\hline Family size & Less than 5 & 221 & 52.4 \\
\hline & Five and above 5 & 201 & 47.6 \\
\hline Marital status & Single & 31 & 7.3 \\
\hline & Married & 344 & 81.5 \\
\hline & Divorce & 26 & 6.2 \\
\hline & Widowed & 21 & 5.0 \\
\hline Religion of household & Orthodox & 264 & 62.6 \\
\hline & Protestant & 52 & 12.3 \\
\hline & Muslim & 106 & 25.1 \\
\hline Main means of income & Merchant & 86 & 20.4 \\
\hline & Government employee & 88 & 20.9 \\
\hline & Private employee & 125 & 29.6 \\
\hline & Daily labour & 112 & 26.5 \\
\hline & Urban Farming & 2 & .5 \\
\hline & Microenterprise & 4 & .9 \\
\hline & Support & 5 & 1.2 \\
\hline Educational level of & Illiterate & 52 & 12.3 \\
\hline & Read and write & 35 & 8.3 \\
\hline & Primary & 102 & 24.2 \\
\hline & Secondary & 155 & 36.7 \\
\hline & Diploma and above & 78 & 18.5 \\
\hline Cigarette smoking & Yes & 62 & 14.7 \\
\hline & No & 360 & 85.3 \\
\hline
\end{tabular}


room that is also used for living/sleeping while 97 (23.0\%) households had separate rooms for cooking and sleeping and $25(6.0 \%)$ households cook outside of the house. The means of ventilation used 125 (52.0\%) households are windows and open doors. However, 115 (48.0\%) households were found to have no proper ventilation.

\section{Association between the prevalence of acute respiratory infections and biomass fuel}

About 145 households (34.4\%) used charcoal, 89 households (21.1\%) used wood fuel, 82 households (19.4\%) used electricity, 76 households (18.0\%) used kerosene, 18 households (4.3\%) used urban residues and leaves, 10 households (2.4\%) used LPG.

The prevalence of ARI observed during the two week period included 76 cases of ARI (29.9\%) in households using biomass fuels (fuel wood, dung cakes, residues and/or charcoal), 16 cases $(21.1 \%)$ in households using kerosene, and 9 cases (9.8\%) in households using clean fuels. The overall prevalence of ARI in the sample was found to be $23.9 \%$.

Bivariate logistic regressions were used to estimate the relative association of household energy use and other exposure variables on ARI. Children of female headed homes were $44 \%$ less likely to have ARI than males (COR 0.56; 95\% CI: 0.35-0.89). Cigarette smoking was associated with ARI. Children living in a smoking family were 2 times more likely to have ARI than that of nonsmokers (COR 1.96; 95\% CI: 1.10-3.49) (Table 2). Mother's behavior towards cooking places in relation to the child's location was also analyzed. Children who were held by their mothers were nearly two times more likely to suffer from an ARI than children who were not held by their mothers while cooking (COR 1.88; 95\% CI: 1.19- 2.95) (see Table 2).

Children live in home without proper ventilation was two times more likely suffering from ARI than in ventilated home (OR 2.41; 95\% CI: 1.34-4.32) (Table 3).

The distribution of children ARI prevalence with respect to fuel and stove type characteristics is summarized in (Table 4). Overall, biomass, kerosene, and all stoves except improved biomass stoves are strongly associated with increased probability of ARI among children.

\section{Multivariate logistics regression analysis of household energy use and other exposure variables on ARI}

Variables that have a p-value less than 0.30 with ARI in a bivariate analysis were subjected to a multivariate logistics regression analysis. fuel use, sex of head of households, cigarette smoking, ventilation, and holding a child on the mothers back while cooking were Included in model (see Table 5).

The odds of ARI was 2.96 (95\% CI: 1.38-3.87) in households using biomass fuel relative to households
Table 2 Bivariate analysis of household characteristics on ARI prevalence in children in Addis Ababa, February 2012

\begin{tabular}{lcc}
\hline Variables & $\begin{array}{c}\text { No. of children } \\
\text { with ARI }(n=422)\end{array}$ & $\begin{array}{c}\text { Crude OR } \\
(95 \% \mathrm{Cl})\end{array}$ \\
\cline { 2 - 3 } & Yes No &
\end{tabular}

\begin{tabular}{|c|c|c|c|}
\hline \multicolumn{4}{|c|}{ Sex of household head } \\
\hline Male & 58 & 227 & $0.56(0.35,0.89)$ \\
\hline Female & 43 & 94 & 1.0 \\
\hline \multicolumn{4}{|l|}{ Family size* } \\
\hline less than five & 54 & 167 & 1.0 \\
\hline Five and above & 47 & 154 & $1.06(0.68,1.66)$ \\
\hline \multicolumn{4}{|l|}{ Educational level } \\
\hline Illiterate & 17 & 35 & $2.22(0.99,5.03)$ \\
\hline Read and write & 10 & 25 & $1.83(0.72,4.65)$ \\
\hline Primary & 24 & 78 & $1.40(0.67,2.94)$ \\
\hline Secondary & 36 & 119 & $1.38(0.70,2.75)$ \\
\hline Diploma and above* & 14 & 64 & 1.0 \\
\hline \multicolumn{4}{|l|}{ Cigarettes smoke } \\
\hline Yes & 22 & 40 & $1.96(1.10,3.49)$ \\
\hline $\mathrm{No}^{*}$ & 79 & 281 & 1.0 \\
\hline \multicolumn{4}{|c|}{$\begin{array}{l}\text { Holding child at backduring } \\
\text { cooking }\end{array}$} \\
\hline Yes & 51 & 113 & $1.88(1.19,2.95)$ \\
\hline $\mathrm{No}^{*}$ & 50 & 208 & 1.0 \\
\hline
\end{tabular}

*reference category.

Table 3 Bivariate analysis of housing \& kitchen characteristics effects on ARI prevalence in children in Addis Ababa, February 2012

\begin{tabular}{lll}
\hline Variables & $\begin{array}{c}\text { No. of children } \\
\text { with ARI }(\mathrm{n}=422)\end{array}$ & $\begin{array}{c}\text { Crude OR } \\
(95 \% \mathrm{Cl})\end{array}$ \\
\cline { 2 - 3 } & Yes $\quad$ No & \\
\hline
\end{tabular}

House type

Made from mud

Brick, stone and block

90

211

2.05(0.76, 5.54)

From both*

6

86

$0.34(0.10,1.19)$

House ventilation

Yes*

5

24

1.0

No

$\begin{array}{ll}16 & 101 \\ 84 & 220 \\ 52 & 151 \\ 17 & 80 \\ 24 & 73 \\ 8 & 17\end{array}$

1.0

Kitchen characteristics

\begin{tabular}{lccc} 
Living room* & 52 & 151 & 1.0 \\
Separate room & 17 & 80 & $0.61(0.34,1.14)$ \\
Separate building & 24 & 73 & $0.96(0.56,1.67)$ \\
Open air & 8 & 17 & $1.37(0.56,3.35)$ \\
\hline
\end{tabular}

${ }^{*}$ reference category. 
Table 4 Bivariate analysis of effects of household fuels use and stove type on ARI prevalence in children in Addis Ababa, February 2012

\begin{tabular}{|c|c|c|c|}
\hline \multirow[t]{2}{*}{ Variables } & \multicolumn{2}{|c|}{$\begin{array}{l}\text { Children with } \\
\text { ARI }(n=422)\end{array}$} & \multirow[t]{2}{*}{$\begin{array}{c}\text { Crude OR } \\
(95 \% \mathrm{Cl})\end{array}$} \\
\hline & Yes & No & \\
\hline \multicolumn{4}{|l|}{ Fuel type } \\
\hline Biomass fuel & 76 & 178 & $3.98(1.88,8.24)$ \\
\hline Kerosene & 16 & 60 & $2.46(1.02,5.94)$ \\
\hline Clean fuels* & 9 & 83 & 1.0 \\
\hline \multicolumn{4}{|l|}{ Stove type } \\
\hline Traditional biomass stove & 37 & 58 & $5.42(2.50,11.76)$ \\
\hline Improved biomass stove & 6 & 28 & $1.82(0.61,5.46)$ \\
\hline Kerosene stove & 18 & 61 & $2.51(1.08,5.81)$ \\
\hline Charcoal stove & 30 & 89 & $2.87(1.32,6.23)$ \\
\hline Clean stove* & 10 & 85 & 1.0 \\
\hline
\end{tabular}

*reference category.

using cleaner fuels after adjusting for sex, smoking, ventilation, child handling behavior. Overall, type of fuel, sex of the household, ventilation, and child handling behavior were important predictors of ARI among under- five children.

\section{Discussion}

Of the study households, biomass fuel (charcoal, fuel wood, residues and dung) was the most widely used fuel for cooking in Addis Ababa. Fewer households use electricity and LPG as cooking fuel, approximately one-fifth of the households sampled.

The result of this study indicated two weeks prevalence of ARI among children under-five years was $23.9 \%$. Nearly, one-fourth of children that are highly vulnerable population groups living in slum area of Addis Ababa were suffering from both upper and lower respiratory infection. This Study was comparable with study conducted in shebadeno southern Ethiopia 21\% [12] and some studies in conducted in Africa, particularly well comparable with ARI prevalence of Ethiopia (24\%) in 2000 [13], Study conducted in Tanzania ARI in the sample was found to be $29.76 \%$ prevalence for children under age 5 in Tanzania [14]. But slightly lower than a study in Zimbabawe shows 16\% children suffered from ARI [15] and Ethiopia national figure prevalence of (13\%) in 2005 [16]. This might be because children in the inner slum city stay in homes being exposed to indoor air pollution from biomass fuel due to space scarcity to stay outside. Underlying risk factors such as malnutrition among children may also aggravate the problems.

The sex of the head of household was significantly associated with ARI prevalence in children. This shows that children who live in male- headed homes less exposed to ARI than female- headed. This result is contrary to existing literature and expected results. A previous study conducted in Ethiopia indicated no significant association of ARI prevalence with sex of household

Table 5 Multivariate analysis effects of fuels used for cooking on ARI prevalence in children in Addis Ababa,

February 2012

\begin{tabular}{|c|c|c|c|c|}
\hline \multirow[t]{2}{*}{ Variables } & \multicolumn{2}{|c|}{ No. of children with ARI $(n=422)$} & \multirow{2}{*}{$\begin{array}{c}\text { Crude OR } \\
(95 \% \mathrm{Cl})\end{array}$} & \multirow{2}{*}{$\begin{array}{l}\text { Adjusted OR } \\
(95 \% \mathrm{CI})\end{array}$} \\
\hline & Yes & No & & \\
\hline \multicolumn{5}{|l|}{ Fuel type } \\
\hline Biomass fuel & 76 & 178 & $3.98(1.88,8.24)$ & $2.96(1.38,3.87)$ \\
\hline Kerosene & 16 & 60 & $2.46(1.02,5.94)$ & $1.96(0.78,4.89)$ \\
\hline Clean fuels* & 9 & 83 & 1.0 & 1.0 \\
\hline \multicolumn{5}{|l|}{ Sex } \\
\hline Male & 58 & 227 & $0.56(0.35,0.89)$ & $0.59(0.36,0.96)$ \\
\hline Female* & 43 & 94 & 1.0 & 1.0 \\
\hline \multicolumn{5}{|l|}{ Smoke } \\
\hline Yes & 22 & 40 & $1.96(1.10,3.49)$ & $2.05(1.11,3.78)$ \\
\hline $\mathrm{No}^{*}$ & 79 & 281 & 1.0 & 1.0 \\
\hline \multicolumn{5}{|l|}{ Ventilation } \\
\hline Yes $^{*}$ & 16 & 101 & 1.0 & 1.0 \\
\hline No & 84 & 220 & $2.41(1.34,4.32)$ & 2.09(1.13,3.87) \\
\hline \multicolumn{5}{|c|}{ Child holding during cooking } \\
\hline Yes & 51 & 113 & $1.88(1.19,2.95)$ & $1.78(1.09,2.87)$ \\
\hline $\mathrm{No}^{*}$ & 50 & 208 & 1.0 & 1.0 \\
\hline
\end{tabular}

*reference category. 
head [12]. A study in urban household in Nigeria also indicated that the sex of household heads did not show any relationship between with the use of biomass fuel use [17]. This inconsistency may be due to socio-economic factors.

Cigarette smoking is also associated with ARI prevalence. Children live in a smoking household are two times more likely to suffer from ARI than that of non-smoking households. This may increase the concentration of indoor air pollution concentration which aggravate ARI in children. This was consistent with the studies conducted in Africa, in Kenya smoking increased the risk of ARI with an odds ratio of 1.48 (95\% CI 1.07-2.04) in the logistics model [2]. Another study also showed that cigarettes smoking increased the risk of ARI from airborne pollutants in young children [17]. Similarly, a Study conducted in an urban slum of India indicated that smoking habits strongly influences the incidence of ARI [18].

This study shows strong associations with increased between biomass fuel and prevalence of ARI in children. Children living in households that are reliant on biomass fuels are about three times more likely to suffer from an ARI compared to children living in homes reliant on clean fuels. This implies that the children exposureresponse for biomass fuel smoke is the most toxic among all the fuel types. This was followed by kerosene and electricity/natural gas. This result similar with most studies conducted in Africa. Study in Zimbabwe showed that children in households using wood, dung, or straw for cooking were more than twice as likely to suffer from an ARI compared to children from households using LPG or electricity [15].

This study was consistent with study in South Africa on children living in households that are reliant on solid fuel are 2 to 4 times more likely to suffer from an Acute Lower Respiratory Infection (ALRI) compared to children living in homes reliant on electricity [19]. But inconsistence with study in Tanzania indicated that the effect of biomass fuel on ARI is the same as the effect of kerosene [20]. A Nigerian study also showed that the use of unclean energy among urban households is confounded with health related problems of IAP [21].

Children who live in households without ventilation were about two times more likely to suffer from an ARI compared to children who live in than in ventilated households. Study indicated child holding at back during cooking is associated with children ARI prevalence. Children in home mother hold child at back while cooking is about two times suffer from ARI). Patterns of time-activity, which place children near sources of pollution such as cooking stoves, contribute to the increased risk of ARI from airborne pollutants in young children [22].

This study provided quantitative snapshot of urban homes using a variety of fuels. Households in this study were grouped based on whether there were children living in the homes and type of cooking fuel used (wood, residues, charcoal, kerosene LPG or electricity). But it is common in Addis Ababa to find one house using more than one fuel. Such grouping home without more information on children from homes using a combination of several fuels may lead to different effect values on children ARI prevalence. ARI was assessed by the use questionnaire which required mothers to explain on the health of their children with respect to ARI in the period two weeks prior to the survey. Since this is not an objective way of collecting health information, the method used to collect health information may have caused underestimation or overestimation of ARI frequency in children.

\section{Conclusion}

Biomass fuel is the dominant fuel used for cooking in Addis Ababa, Ethiopia. This study shows strong associations between biomass fuel and prevalence of ARI in children under-five year. Apart from family size, educational level and kitchen characteristics others factors like sex of head of house hold, cigarette smoking habits, fuel type, ventilation, holding child at back while cooking a influence the prevalence of ARI in children under-five. Therefore, an effective mitigation strategy should employ multiple interventions such as improvements in fuels, cooking technologies, ventilation conditions. Additional behavior adjustments such as ensuring children are kept away from smoke and not smoking in closed range of children. The relationship needs to be further investigated using more direct measures of IAP exposure and clinical measures of acute respiratory infection needed to confirm the association. Other cofounders like nutritional status, immunization status, and behavior should also be studied.

\section{Competing interests}

The authors declare that they have no competing interests.

\section{Authors' contributions}

HS was the principal investigator of the study and took the leading role from origin, design and supervising data collection process to the final analysis and preparation of the manuscript. AA and AK participated in the supervise study and reviewing the whole document and provided critical comments. All authors read and approved the final manuscript.

\section{Acknowledgements}

We would like to thank the Addis Ababa University's Environmental Science program and Environmental and Development Action of Ethiopia (ENDA Ethiopia) for their financial support. Moreover, support from the EPA is highly appreciated. Furthermore, we would also like to acknowledge Addis Ababa Health Bureau and the woreda health office for their relevant support. Finally, we thank Addis Ababa health extension workers, field workers, supervisors, the mothers, and other caretakers of study children who participated in this study.

\section{Author details}

${ }^{1}$ Department of Public and Environmental Health, College of Medicine and Health Science, Hawassa University, Hawassa, Ethiopia. ${ }^{2}$ Department of Physics and Center for Environmental Sciences, College of Natural Sciences, Addis Ababa University, Addis Ababa, Ethiopia. ${ }^{3}$ School of Public Health, College of Health Sciences, Addis Ababa University, Addis Ababa, Ethiopia. 


\section{References}

1. World Health Organization (WHO): Indoor Air pollution: National Burden of Disease Estimates. France: WHO; 2007.

2. Ezzati M, Kammen DM: Indoor air pollution from biomass combustion and acuterespiratory infections in Kenya: an exposure-response study. Lancet 2001, 358:619-629.

3. Smith KR, Aggarwal AL, Dave RM: Air pollution and rural biomass fuels in developing countries: a pilot village study in India and implications for research and policy. Atmos Environ 1983, 17(11):2343-62.

4. Wood TS, Baldwin S: Fuelwood and charcoal use in developing countries. Ann Rev Energy 1985, 10:407-29.

5. National Meteorological Services Agency (NMSA): Federal Democratic Republic of Ethiopia Ministry of Water Resources Initial National Communication of Ethiopia to the United Nations Framework Convention on Climate Change. Addis Ababa: UNFCCC; 2011.

6. Kumie A, Yemane B: Crowding in a traditional rural housing ("Tukul") in Ethiopia. Ethiop J Health Dev 2003, 16(3):25-40.

7. Sanbata H, Asfaw A, Kumie A: Indoor air pollution in slum neighbourhoods of Addis Ababa, Ethiopia. Atmos Environ 2014, 89:230-234.

8. CSA and ICF-International: Ethiopia Demographic and Health Survey 2011. Addis Ababa and Calverton, Maryland, Ethiopia and USA: Central Statistical Agency and ICF International; 2012.

9. United Nations Human Settlements Programme (UN-HABITAT): Situation Analysis of Informal Settlements in Addis Ababa, Cities without Slums SubRegional Programme for Eastern and Southern Africa, Addis Ababa Slum Upgrading Programme. Nairobi: UN-HABITAT; 2007. ISBN 92-1-131863-7.

10. World Health Organization (WHO): Technical Bases for the WHO Recommendations Onthemanagement of Pneumonia in Children at First-Level Health Facilities. Geneva: World Health Organization; 1991.

11. World Health Organization (WHO): ARl: Programme Review for Control of Acute Respiratory Infections. Sixth Programme Report. Geneva: World Health Organization; 1993.

12. Biruck $D$, Araya A, Suleiman $H$ : Household fuel use and acute respiratory infections among younger children: an exposure assessment in Shebedino Wereda, Southern Ethiopia. Afr J Health Sci 2011, 18(2):31-36.

13. EDHS: Demographic and Health Survey report, Ethiiopia. ORC Marco, Cavelrton, Maryland, USA: Central Stastistical Authority; 2005.

14. Kilabuko JH, Hidieki M, Satoshi N: Air quality and acute respiratory illness in biomass fuel using homes in Bagamoyo, Tanzania. Int J Environ Res Public Health 2007, 4(1):39-44.

15. Mishra V: Indoor air pollution from biomass combustion and acute respiratory illness in preschool age children in Zimbabwe. Int J Epidemiol 2003, 32(5):847-53.

16. EDHS: Demographic and Health Survey report, Ethiiopia. ORC Marco, Cavelrton, Maryland, USA: Central stastistical Authority; 2011.

17. Smith KR, Samet JM, Romieu I, Bruce N: Indoor air pollution in developing countries and acute lower respiratory infections in children. Thorax 2000, 55(6):518-32.

18. Sharma S, Sethi GR, Rohtagi A, Chaudhary A, Shankar R, Bapna JS, Joshi V, Sapir DG: Indoor air quality and acute lower respiratory infection in Indian Urban Slums. Environ Health Perspect 1998, 106(5):291-297.

19. Barnes B, Angela M, Elizabeth T, Nigel B: Household energy, indoor air pollution and child respiratory health in South Africa. J Energy South Afr 2009, 20(1):12-13.

20. James HK, Satoshi N: Effects of cooking fuels on acute respiratory infections in children. Int J Environ Res Public Health 2007, 4(4):283-288.

21. Usman $R$, Sheu $A$ : Correlates and health on consequences of indoor air pollution among urban households in llorin, Nigeria. Glob J Hum Soc Sci 2010, 10(4):80-87.

22. Lohani SP: Biomass as a source of household energy and indoor air pollution in Nepal. Iran J Energy Environ 2011, 2(1):74-78.

\section{doi:10.1186/1471-2458-14-1122}

Cite this article as: Sanbata et al:: Association of biomass fuel use with acute respiratory infections among under- five children in a slum urban of Addis Ababa, Ethiopia. BMC Public Health 2014 14:1122.

\section{Submit your next manuscript to BioMed Central and take full advantage of:}

- Convenient online submission

- Thorough peer review

- No space constraints or color figure charges

- Immediate publication on acceptance

- Inclusion in PubMed, CAS, Scopus and Google Scholar

- Research which is freely available for redistribution 